III. LA SUSPENSIÓN DE GARANTÍAS JUDICIALES SEGÚN LA CORTE INTERAMERICANA DE DERECHOS HUMANOS

JOSÉ MIGUEL ONAINDÍA

Universidad de Buenos Aires 
SUMARIO

INTRODUCCION.-I. BREVE REFERENCIA SOBRE LOS ORGANISMOS INTERNACIONALES INTERAMERICANOS PARA LA PROTECCIÓN DE LOS DERECHOS HUMANOS.-III. ESTAdOS DE EMERGENCIA.-III. OPINIONES CONSULTIVAS DE LA CORTE INTERAMERICANA.-1. Opinión Consultiva 8/87. 2. Opinión Consultiva 9/87. IV. CONCLUSIÓN. 


\title{
III. LA SUSPENSIÓN DE GARANTÍAS JUDICIALES SEGÚN LA CORTE INTERAMERICANA DE DERECHOS HUMANOS
}

\author{
POR \\ JOSÉ MIGUEL ONAINDIA \\ Universidad de Buenos Aires
}

INTRODUCCIÓN

El objeto central de este trabajo es divulgar la tarea efectiva, aunque silenciosa, que desarrolla este órgano regional para la protección de los derechos humanos.

El sistema interamericano ha sido precursor de la consagración internacional de estos derechos, ya que la Declaración Americana de los Derechos y Deberes del Hombre, formulada por la OEA en abril de 1948, precedió en varios meses a la Declaración Universal. Pero sólo la actividad de sus organismos de protección ha permitido que este documento y sus convenciones complementarias cumplan su finalidad y excedan al marco de una elogiable práctica retórica.

He elegido para éste análisis la función menos difundida pero más frecuente de la Corte, su competencia consultiva. $Y$ dentro de este plano de su actividad, la que ejerció respecto de una cuestión que afecta especialmente al continente americano: la suspensión de garantías y derechos durante los estados de emergencia. La frecuencia con que se declaran estas situaciones en los diversos países de la región y la utilización de estas potestades constitucionales de los Estados miembros de la organización para dotar de aparente legalidad hechos violatorios de los derechos del hombre, otorgan a las opiniones consultivas de la Corte que más adelante analizaremos, un interés particular para la comprensión del sistema protectorio. 


\section{BREVE REFERENCIA SOBRE LOS ORGANISMOS INTERAMERICANOS PARA LA PROTECCIÓN DE LOS DERECHOS HUMANOS}

La protección de los derechos humanos en el sistema regional interamericano se ejerce a través de dos órganos específicos regulados en la Convención Americana de Derechos Humanos (Pacto de San José de Costa Rica de 1969). Estos órganos son la Comisión Interamericana de Derechos Humanos (preexistente a la Convención) y la Corte Interamericana de Derechos Humanos.

La Comisión tiene la función de promoción de los derechos humanos en los Estados miembros de la Organización, pero también tiene competencia para conocer denuncias o quejas de violación de derechos presentadas por particulares o entidades no gubernamentales. En este último caso desarrolla un procedimiento de investigación que concluye en un informe y no implica el ejercicio de atribuciones jurisdiccionales. Debe recordarse la actividad cumplida por la Comisión en los casos chileno (1974) y argentino (1979) (ver G. CARRIÓ: Los Derechos Humanos y su Protección. Abeledo-Perrot, pág. 46).

La Corte, en cambio, es un típico órgano internacional de carácter jurisdiccional ante el cual están legitimados para actuar los Estados parte de la Convención y la Comisión.

Para que la Corte conozca de un caso es necesario haber agotado el procedimiento ante la Comisión (artículo 61, Pacto de San José de Costa Rica). En ejercicio de esta competencia litigiosa, y como conclusión de este procedimiento, el órgano dicta un fallo motivado, definitivo e inapelable. Este pronunciamiento, si decide que existe una violación a un derecho o una libertad, ordenará que cesen los actos que perturban el goce del derecho y podrá ordenar la reparación del daño causado.

Además de esta actividad jurisdiccional, la Corte, a requerimiento de los Estados miembros, puede evacuar consultas acerca de la interpretación de la Convención o de otros tratados concernientes a la protección de los derechos del hombre en los Estados americanos (artículo 64 del Pacto de San José de Costa Rica). También pueden solicitar el dictado de una opinión consultiva diferentes órganos integrantes de la OEA (Asamblea General, Reunión de Consulta de los Ministros de Relaciones Exteriores, Consejo Permanente, Consejo Interamericano para la Educación, la Ciencia y la Cultura; Comité Jurídico Interamericano; Comisión Interamericana de Derechos Humanos, Secretaría General). En ejercicio de esta facultad interpretativa la Corte ha emitido diversas opiniones consultivas que han contribuido a la articulación correcta del sistema. De esta forma se despejan dudas sobre los alcances de una disposición del pacto u otro convenio 
internacional sobre la materia y se fija la interpretación acertada de estas normas (ver Las dimensiones Internacionales de los Derechos Humanos. K. VASAK, UNESCO, t. III, págs 706 y ss.).

\section{ESTADOS DE EMERGENCIA}

Toda comunidad está expuesta a atravesar por situaciones que alteren el normal desarrollo de su vida institucional y la obliguen a adoptar medidas de excepción. Estas circunstancias, llamadas "emergencias", adquieren en el Derecho americano un sitio relevante, pues la convulsionada realidad política, social y económica de la mayoria de los países de la región, han otorgado a estas situaciones una triste pero innegable cotidianeidad.

La inestabilidad política, la pobreza, el terrorismo o el narcotráfico, son hechos que han impulsado a las autoridades de diferentes países a recurrir a la declaración de un estado de emergencia para afrontar estos $\mathrm{u}$ otros hechos similares. Estos datos de la realidad regional no fueron desconocidos por los redactores de la Convención de Derechos Humanos y en el artículo 27 del Pacto se regularon los casos en que procede declarar estos estados de excepción.

Si bien la norma tiene por título "La suspensión de garantías», de su lectura se deduce que no sólo pueden suspenderse garantías -entendidas éstas como mecanismos de protección de los derechos-, sino también que es posible suspender el ejercicio de determinados derechos, con exclusión de los mencionados en el inciso 2 del artículo 27.

El primer inciso de la norma citada fija las condiciones para que proceda la suspensión de garantías y derechos. Se establece cuáles son los supuestos fácticos de la suspensión: «En caso de guerra, de peligro público o de otra emergencia que amenace la independencia o seguridad del Estado parte...».

Solamente ante estos hechos puede declararse la emergencia, aunque la norma no exige una proclamación oficial del Estado parte, tal como lo hace el artículo 4.2 del Pacto Internacional (cfr. C. ColautTI: El Pacto de San José de Costa Rica, págs. 138 y ss.).

Ante estos hechos el gobierno puede adoptar disposiciones que en la medida y por tiempo estrictamente limitado a las exigencias de la situación, suspendan las obligaciones contraídas en virtud de esta Convención... "Surge así la limitación temporal del estado de emergencia como una condición esencial de su validez». 
La suspensión aludida puede decretarse siempre que no sea ... «incompatible con las demás obligaciones que le impone el derecho internacional y no entrañen discriminación alguna fundada en motivos de raza, color, sexo, idioma, religión u origen social». Se ratifica aquí el espíritu netamente antidiscriminatorio.

En el inciso $2 .^{\circ}$ se enumeran los derechos que no pueden suspenderse en ninguna circunstancia. Estos son: el derecho al reconocimiento de la personalidad jurídica (art. 3), derecho a la vida (art. 4), derecho a la integridad personal (art. 5), prohibición de la esclavitud y la servidumbre (art. 6), principio de legalidad y retroactividad (art. 9), libertad de conciencia y de religión (art. 12), protección a la familia (art. 17), derecho al nombre (art. 18), derechos del niño (art. 19), derecho a la nacionalidad (art. 20) y derechos políticos (art. 23).

Además, la norma agrega que tampoco podrán suspenderse las garantías judiciales indispensables para la protección de tales derechos.

Por último, el inciso $3 .^{\circ}$ del artículo 27 establece para el Estado parte la obligación de informar a los demás Estados parte en la Convención a través del secretario general de la Organización de Estados Americanos, los motivos que condujeron a resolver la suspensión, las disposiciones del Pacto que haya suspendido en virtud de tales motivos y la fecha de conclusión del estado de emergencia. Esta norma repite casi textualmente lo dispuesto en el artículo 4.3 del Pacto Internacional.

De la lectura de la norma podemos apreciar los estrictos requisitos que rodean a estas situaciones de excepción y la imposición de deberes internacionales que influyen sobre la prudencia de los Estados parte antes de adoptar estas medidas de extrema gravedad.

\section{OPINIONES CONSULTIVAS DE LA CORTE INTERAMERICANA}

La Corte fue consultada sobre los alcances de esta disposición del Pacto y su compatibilidad con otras normas integrantes de la Convención.

\section{Opinión Consultiva $8 / 87$}

La Opinión Consultiva 8/87 (30-1-1987) fue solicitada por la Comisión Interamericana de Derechos Humanos. Ante el petitorio, la Corte, en virtud 
de lo dispuesto en el artículo 52 de su Reglamento, solicitó observaciones a todos los miembros de la OEA y a los órganos habilitados para requerirle opiniones consultivas.

Tal comunicación fue respondida por los Gobiernos de Venezuela, Panamá y Ecuador, y ofrecieron sus puntos de vista, como amici curiae, las siguientes organizaciones no gubernamentales: American Watch, Committee e International Human Rights Law Group. Luego se celebró una audiencia con objeto de que la Corte recibiera las opiniones de los Estados miembros y órganos de la OEA.

La consulta fue formulada en los siguientes términos:

«El recurso de habeas corpus, cuyo fundamento juridico se encuentra en los artículos 7.6 y 25.1 de la Convención Americana de Derechos Humanos, es una de las garantias judiciales que, de acuerdo a la parte final del párrafo 2 del artículo 27 de esa Convención, no puede suspenderse por un Estado parte de la citada Convención Americana».

Según la Comisión, motivó la consulta el hecho de que muchos Estados parte de la Convención han entendido que en los estados de emergencia la protección judicial que se ejerce mediante el habeas corpus es una de las garantías que puede suspenderse. Destaca que incluso en algunos paises se ha promulgado una legislación especial o se ha llevado a la práctica la detención de personas con incomunicación por períodos prolongados, impidiendo el planteo del recurso de habeas corpus durante el periodo de incomunicación.

Antes de entrar a la consideración del fondo del asunto, la Corte aclara que la interpretación de las normas requeridas por la Comisión, la efectuará conforme las reglas de la Convención de Viena sobre el derecho de los Tratados, que en su artículo 31.1 dispone que un tratado deberá interpretarse de buena fe y teniendo en cuenta su objeto y fin. Además recuerda lo normado en el artículo 29 del Pacto sobre la interpretación de sus cláusulas, en cuanto prohíbe que la interpretación se efectúe en desmedro del goce y ejercicio de los derechos consagrados en la Convención.

El órgano estima que el artículo 27.1 contempla distintas situaciones y que las medidas que se adopten en cada una de ellas deben armonizar con los hechos que le dan origen. La juridicidad de tales medidas dependerá de su proporcionalidad con las situaciones que intenta enfrentar, ya que la razonabilidad del medio empleado es un elemento determinante de su legitimidad. La suspensión de garantías no implica la suspensión temporal del Estado de Derecho ni autoriza a los gobernantes a apartar su conducta de la legalidad a la que siempre se hayan sometidos. La ampliación de facultades durante los estados de excepción no debe confundirse con la asunción de poderes absolutos los que siempre están vedados en una sociedad democrática. Luego la Corte efectúa una apreciación sobre el concepto de garantías y expresa al respecto: «... El concepto de derechos 
y libertades $y$, por ende, el de sus garantías, es también inseparable del sistema de valores y principios que lo inspira. En una sociedad democrática, los derechos y libertades inherentes a la persona, sus garantías y el Estado de derechos constituyen una tríada, cada uno de cuyos componentes se define, completa y adquiere sentido en función de los otros... En condiciones de grave emergencia es lícito suspender temporalmente ciertos derechos y libertades cuyo ejercicio pleno, en condiciones de normalidad, debe ser respetado y garantizado por el Estado, pero como no todos ellos admiten esa suspensión transitoria, es necesario que también subsistan las garantías judiciales indispensables para su protección...».

También destaca que si bien el artículo 27.2 no vincula las garantias que menciona a ninguna disposición del Pacto, a través de esa aparente omisión está indicando que debe determinarse en cada caso si esos procedimientos son indispensables para garantizar los derechos que no pueden ser afectados por la emergencia.

Pero las garantias además de ser indispensables deben ser judiciales, es decir, que deben consistir en procedimientos jurisdiccionales idóneos para la protección del derecho afectado. De esta forma se garantiza la intervención de un órgano judicial independiene del poder administrador, con capacidad para determinar la legalidad del procedimiento utilizado.

La Corte considera luego si a pesar de que los artículos 7 y 25 de la Convención no estén mencionados en el artículo 27.2, las garantías que ellos consagran deben ser consideradas «indispensables» para la protección de los derechos no susceptibles de protección.

Es necesario aclarar que el artículo 25 consagra la institución procesal del "amparo", mientras que el artículo 7.6 regula el habeas corpus. Dado que el amparo es un procedimiento rápido que tiene por objeto la tutela de todos los derechos constitucionales de cada Estado parte, también es aplicable para la protección de los derechos insusceptibles de suspensión según el artículo 27.2. Por su parte, el habeas corpus tiene el objeto específico de proteger la libertad física o de locomoción, en principio no enumeradas en la norma citada. Pero la Corte destaca que al exigir este procedimiento «... la presentación del detenido ante el juez o Tribunal competente bajo cuya disposición queda la persona afectada...", cumple una función esencial para controlar el respeto a la vida e integridad física de la persona, para impedir su desaparición o la indeterminación del lugar de detención y para protegerlo contra la tortura u otros tratos infamantes. Por tales argumentos la Corte por unanimidad opinó:

«Que los procedimientos jurídicos consagrados en los artículos 7.6 y 25.1 (acción de amparo y habeas corpus) de la Convención Americana sobre Derechos Humanos no pueden ser suspendidos conforme el artículo 27.2 de la misma, porque constituyen garantías judiciales indispensables para proteger derechos y libertades que tampoco pueden suspenderse según la misma disposición». 


\section{Opinión Consultiva $\mathbf{9 / 8 7}$}

En el mismo año, y ante el requerimiento del Gobierno uruguayo, la Corte tuvo oportunidad de emitir opinión sobre una cuestión similar: en este caso se solicitó que la Corte se pronunciara sobre el alcance de la expresión «garantías judiciales indispensables» (art. 27.2 del Pacto) y su relación con los artículos 8 y 25 (Derecho al debido proceso). En cuanto hace a la interpretación del artículo 8 de la Convención, la Corte establece que «... el concepto de debido proceso legal recogido por el artículo 8 de la Convención debe entenderse como aplicable, en lo esencial, a todas las garantías judiciales referidas a la Convención Americana, aun bajo el régimen de suspensión regulado por el artículo 27 de la misma...».

Es decir, que los principios del debido proceso legal (presunción de inocencia, derecho de defensa, prohibición de coacción, etc.) no pueden suspenderse durante los estados de excepción pues son elementos sustanciales para considerar a los procedimientos garantías judiciales indispensables.

Por tanto, en esta nueva opinión consultiva sobre las garantias vigentes en los estados de excepción, la Corte agregó a lo ya dicho en anterior oportunidad, la siguiente opinión:

«También deben considerarse como garantías judiciales indispensables que no pueden suspenderse, aquellos procedimientos judiciales inherentes a la forma democrática, representativa de gobierno (art. 29 del Pacto), previstos en el derecho interno de los Estados parte como idóneos para garantizar la plenitud del ejercicio de los derechos a que se refiere el artículo 27.2 de la Convención y cuya supresión o limitación comporte la indefensión de tales derechos».

"Las mencionadas garantías judiciales deben ejercitarse dentro del marco y según los principios del debido proceso legal, recogidos en el artículo 8 de la Convención».

En consecuencia, el derecho al debido proceso legal debe considerarse también insusceptible de suspensión, ya que constituye el presupuesto de garantías judiciales aludidas en el artículo 27.2 del Pacto.

\section{CONCLUSIÓN}

De esta forma la Corte ha marcado los exactos límites al ejercicio de esta peligrosa y necesaria facultad estatal y ha destacado que no existe Estado de Derecho sin mecanismos que tornen exigible su respeto. 
Creo que uno de los hechos más relevantes de nuestro siglo ha sido el surgimiento de la internacionalización de los derechos humanos en sus dos vertientes: universal y regional. La actividad complementaria de los organismos integrantes de ambos sistemas permitirá desarrollar la convicción de que el principio de soberanía estatal no es oponible ante una situación en la que se discuta el alcance, validez o transgresión de un derecho. 